\title{
On the Key Points in the Construction of Education and Self-education Classroom System
}

\author{
Zhimin Lei \\ School of Marxism, Sichuan Agricultural University, Chengdu, Sichuan, China \\ E-mail:1007930161@qq.com
}

Keywords: Ideological and Political Theory Course, Educating People, Education and Self-education, Classroom System, Key Points

\begin{abstract}
China's Outline of National Medium-and Long-Term Program for Education Reform and Development pointed out that it is necessary to "take educating people as the fundamental requirement of educational work." In the teaching reform of ideological and political theory in western Chinese universities, Sichuan Agricultural University gradually formed an undergraduate "education and self-education classroom system" that abides by the principle of educating people through curriculum reform practice. The system has practical and demonstration significance to promote the teaching reform of theoretical courses in colleges and universities and to construct a classroom teaching system that strengthens moral education and cultivates people.
\end{abstract}

\section{Foreword}

Educating people is the fundamental requirement of educational work. The National Education Plan of China states that "we should firmly establish the central position of talent cultivation in the work of colleges and universities and strive to cultivate high-quality professionals and top-notch creative talents with strong moral qualities, knowledge and skills. It is clearly pointed out that the primary criterion is "perseverance and good moral character", that is, to uphold moral education first. Colleges and universities are important fronts for the study of Marxism, discipline construction and talent cultivation. Theoretical classroom teaching is the main field for ideological and political education in universities and the main channel for educating people. Only by adapting to the needs of national and social development, following the laws of education and talent growth, deepening the reform of education and teaching, innovating the teaching methods of education, and exploring various ways of training, ${ }^{[1]}$ can reliable successors and qualified workers in the socialist cause with both ability and political integrity be cultivated through the teaching of ideological and political theory.

So, how to realize "perseverance and good moral character" which are the first element of high-quality specialized talents and top-notch creative talents in the practical theory teaching? How to integrate socialism into theoretical teaching so as to realize the healthy growth of college students and the sustainable development of ideological and political education? In the recent four years of theoretical reform of teaching in colleges and universities, according to the actual situation of undergraduates in western universities, Sichuan Agricultural University follows the principle of educating people, gradually forming a student-centered college students' "education and self-education classroom system", achieving effectiveness and relevance of ideological and political education. Teaching experiments in the past three years show that building an education and self-education classroom system that focuses on the healthy growth of students must reinforce the following three key points:

\section{Adhere to the Fundamental principles of Marxism guidance and teacher-centeredness}

Taking college students as the foundation, do not let the ideological and political theory classrooms to be filled with pluralistic thoughts. Instead of putting teachers in the inferior position 
and indulging in the proliferation of various ideological trends while rejecting their dominance and neglecting their subjectivity., as a teaching subject that coexists with students, theoretical teachers must unswervingly uphold the dominance of the guiding ideology of Marxism and hold the leading position of teachers' scientific thinking. Adhere to the guiding principle of Marxism and the dominant position of teachers, teaching methodology is to teach students in accordance with their aptitudes, to awaken the students' rational thinking, unite the core values of socialism with Chinese characteristics in the collision of ideas, which are the core tasks of theoretical education workers. Therefore, it is imperative for students to pay attention not to move from one extreme to the other, from "teacher-dominant class" to the extreme "group speaking hall", so that the teacher loses the responsibility of the commanders in the theoretical positions and loses the front for preaching Marxism.

The basic principle of upholding the guiding ideology of Marxism and the dominant position of teachers is not to establish the absolute authority of teachers in teaching. The essence is to realize the organic unity of democracy and concentration in the classroom through the organic combination of diversity and dominance in education and teaching. The aim is to elevate the banner of Marxist theory, uphold the common ideal of socialism with Chinese characteristics, and make profound theories a straightforward guide to life. Let the theory of science be internalized into the scientific concept of correct life, values and worldview of college students, and be turned into life and practice bit by bit. Therefore, the dominant core of the teachers is the unshakable ground that occupies the high school theoretical class with the theory of scientific socialism, so that the Marxist theory and the theory of socialism with Chinese characteristics are truly recognized and promoted by the students as the guiding ideology of social development in China. This is the core of the successful operation of the new system and the tenet of the new curriculum reform.

There are a lot of teaching reform tests with the same nature, some have triggered some thinking. For example, in order to cater to students' curiosity or converse thinking, some teachers talk wildly and play trilogy, take a variety of forms of student learning or autonomy to discuss, compete or make speech or multimedia presentations in order to achieve the teaching objectives, attracting many participants while achieving a lively atmosphere. The final education reform survey shows that most students think that the interactive teaching activities in middle schools are more exciting, and the activity of university theoretical classroom activities is seemingly active and participative, but there is no actual theoretical gains through rational analysis. What is the standard for successful theoretical learning? A rational evaluation of contemporary college students is that they have both breadth and depth of theoretical study, both easy to understand and have rational thinking.

\section{Adhere to the healthy development of college students as the basic principle}

College students who were born after 1995 or 2000 live in the best times of socio-economic development and personal development since the founding of the People's Republic of China. They are good at thinking independently, dare to break the restricted area, have a broad vision and pay attention to reality. However, they are also facing unprecedented harsh challenges, complex realities and a diversified network of information society. Both the ideological field and the economic field are characterized by diversity and variety, which profoundly affect the ideological awareness and value orientation of college students. College ideological and political education is facing unprecedented challenges. Facing a world with a wide range of awareness and networks, newly emerging ideas and materials, traditional teaching style and teaching system taking teachers as the center and textbooks as the only resource is completely unsuitable for college students' cognitive level and ideological needs and the comprehensive development needs. They need mentors to guide and ease mental confusions, and need to improve the overall quality and ability to analyze and solve problems.

The objective reality and the subjective needs of college students urge teachers to have an open consciousness, a sense of democracy and science, so as to earnestly establish the concept of education and teaching centered on the students and their healthy development. Learning is a dynamic and equal process. Students are the main body of cognition who can think, explore and 
discover by themselves. Classroom teaching is the main carrier of this process, enabling teachers and students to make meaningful learning and experience of life equally. According to Carl Rogers, the most effective way to learn is to allow students to experience the practical problems they face, and the teacher's job is to give students the opportunity to do so.[2] The "education and self-education classroom system" built by Sichuan Agricultural University essentially embodies the student-oriented learning and experience-based learning community.

The special meaning of "education and self-education classroom system", which has the nature of ideological and political course, lies in being a practical way to explore the successors to the cause of socialism with Chinese characteristics. The learning of Marxist theory is not for theoretical study, but for college students to ideologically and truly understand the Marxism from reality. That is to say, starting from solving the students' ideological confusion and existing cognitive structures and cognitive rules, think what they think and solve what they confuse. A new teaching system based on healthy growth of students should guide diverse thinking, strengthen ideals and convictions with scientific thinking, common ideal, spirit of the times and good quality.

\section{Build a "1 Team + 2 Types" mechanism}

The ancient poem reads: "The river is always keeping clean, since there is inflowing water from its source." Similarly, to make ideological and political education internalize students' ideals and beliefs and externalize them to serve the society and people, we must work hard under the word "living" and emphasize the word "acting." We should build a "1 Team +2 Types" teaching community together with teachers by fully mobilizing the enthusiasm of students with the mentality of the host to participate in teaching.

\section{1 “1 Team” is to establish a student management team centered on class representatives}

"Only when the object of education becomes the subject can the ideological and political education process gain its integrity again."[3] In order to fully develop students' initiative, Sichuan Agricultural University teaching reform experiments set up a student management team management according to the wishes of students. Under the guidance of teachers, a teaching assistant is created on the principle of voluntariness and dedication. A student management team mainly composed of small-scale study committees with curriculum representatives as the core who assist teachers and lead small classes to effectively carry out classroom teaching and research. The management team has three major tasks. First, it is responsible for the questionnaire survey of pre-school students, collecting and arranging the relative ideas and theoretical problems of relatively concentrated students' confusion as the basic basis for teaching reform in class discussions, keynote speeches, thematic dissertations, course dissertations and appraisals. Second, it is responsible for the questionnaire survey before the end of the course so as to feedback and evaluate the effect of teaching reform, laying the groundwork for a new round of educational reform experiment. Third, it establishes management team QQ group, public mail and other network communication channels. Student management team accepts the guidance of the teachers, and collects dynamic thinking and feedback of the majority of students. This is an organizational guarantee for the successful operation of education and self-education in classroom teaching.

\section{2 "2 Types" is to use various educational resources to create a "thematic" "participatory" hybrid teacher-student and student-student education platform}

\subsection{1 “Thematic" type}

Chinese traditional culture has a saying of "a gentleman being not only a tool"[4]. At present, the essence of the ideological and political education in socialism with Chinese characteristics lies in solving the problem of college students' ideological understanding, establishing a correct outlook on life, world outlook and values, correctly grasping the law of social development, and creating a reliable successor to the cause of socialism with Chinese characteristics. We must have the socialist core values of socialism with Chinese characteristics. "In any society, in order to survive, it is 
essential to successfully inculcate members of society into thinking that is appropriate to maintain their worth."[5] To this end, Sichuan Agricultural University tries its best to make ideological and political education work according to circumstances in the teaching reform experiment with "thematic" and "linkage" effort. In view of the diversified status quo of thinking in the era of network times, the cognitive characteristics of students, ideological and political education teaching objectives and the reality, while taking full advantage of the educational opportunity of Memorial Day, Sichuan Agricultural University conducted a docking analysis of teaching contents and students' cognitive thinking puzzles by way of pre-school questionnaire, sorting out 10 teaching topics in different categories as the key content of the whole teaching. For example, the teaching experiment of "Compendium of Modern and Contemporary Chinese History" combines teaching objectives, student confusion and current political issues to determine teaching topics or discuss topics. Taking the opportunity of celebrating the 60th anniversary of the founding of People's Republic of China, the theme of "the historic inevitability and feasibility of China's choice of socialism in modern and contemporary China and foreign countries" is determined." Taking the 100th anniversary of the Revolution of 1911 as an opportunity to analyze the practice of the separation of the three powers in the West and bipartisan system in modern China and its results. Taking the 100th anniversary of the Soviet Union and Russia's October socialist revolution in 2017 as an opportunity to formulate a theme discussion on why the Chinese people have chosen Marxism since the modern era. In this way, under the guidance of teachers, the contradiction between the rigid requirements of teaching content and students' diversified needs an between the confusion of students and short teaching time can be properly handled, students' subjective status can be fully respected, the main teaching content of ideological and political theory can be grasped. By using Memorial Day and other educational opportunities, through targeted teaching topics and methods, teacher-student and student-student education as swell as self-education can be carried out, achieving the effectiveness of education. Some scholars pointed out that "the fundamental difference between the process of human knowledge transfer and the transfer of animal instinct lies in the human knowledge transfer process is to evoke the subjectivity of the educated"[6], thematic teaching combined with the students' actual thinking and theoretical perplexity, organizing teaching in a thematic form, organic integration of unity and individuality, and stimulating college students to explore the truth with great enthusiasm for the study of the theory.

\subsection{2 "Participatory" type}

From the epistemological point of view, the educated is the subject, the educator is the object, the educator plays the leading role, but the leading role of the educator can not replace the dominant position of the educated. The process of education is actually a two-way interaction between educators and educated people on the basis of equality. According to the principle of pedagogy and the actual situation of students, we designed interactive platforms such as "ten minutes before class" and "I talk about theory" to explore "teacher teaching + student teaching" interactive teaching, achieving teaching interaction between teachers and students. For example, the "ten minutes before class" lecture mechanism is set up as: all the small classes presided by the class representatives are implemented alternately and the preparation process is included in the daily schoolwork assessment of each small class. Commented on a topic around "Yesterday - Today - Tomorrow" for ten minutes, once or twice a week. The content consists of "Today in History" and the related "Brief Review of Current Events." Themes set dynamic management, combined with the current political issues and hot issues. Diverse forms such as lectures, melodramas or debates are adopted, but teacher reviews are required. Student-student interaction promotes thoughts of the entire classroom, a few rounds of experiments have gained good effect. "I talk about theory" discussion mechanism is set up as: the activity speaks and discusses for various forms of topics. In order to fully motivate the students as the main elements to participate in theoretical study, the theme of "I'll Speak" was put forward and presided over by the Learning Committee according to the teaching theme one after another. The teachers prepare and review the teaching materials according to the progress of teaching and hot issues of the politics. Students participate in groups (presenters and attendees), provide multimedia 
tools and promote group discussions in small groups, or adopting multi-media presentations, debates, or other forms of practical teaching that are supplemented by situational performances. Time is set to 15 minutes to 20 minutes, appropriate 5 times are arranged a semester depending on the teaching schedule. Experiments show that whether "ten minutes before class", "I talk about theory", students interaction or interaction between teachers and students, whether it is to examine the motivation or incentive psychological hint, all students truly get involved, demonstrating that self-motivation is the recipe to establish goals and strive to achieve it[7].

In fact, "thematic" and "participatory" types are interdependent and together provide a platform for teacher-student and student-student education as swell as self-education. The experimental group of "A Course Outline of Modern and Contemporary History" conducted a questionnaire survey on students who received the experiment of educational reform. "What do you think is the best way to teach modern Chinese history?" - A. Watch documentaries; B teacher instruction; C teacher instruction combined with student discussion; D Other. The result is: $35.17 \%$ chose A, 7.15\% chose B, 57.14\% chose C. As for the result, the students of the Grade 2008 analyzed that "From this ratio, we can see that the most popular teaching method is teacher instruction combined with student discussion. The reasons are also quite obvious, simply watching the documentary seems to be too tedious, ignoring the guiding role of teacher, so the teaching effect is relatively low. If only teachers teach students not to participate in the discussion, it is difficult to mobilize students' enthusiasm for learning. In addition, the teacher will feel tired and teaching effectiveness is not good, students may not want to listen to the teacher's nagging. The combination of teacher instruction and student discussion can be described as the best of both worlds. It not only considers the problems of mobilizing students' enthusiasm, but also enables students to express their opinions on historical events and some different opinions. This will also help students to think independently to analyze problems while alleviating teaching routine time. Teachers will also be able to participate in discussions, make excerpts and strengthen students' historical knowledge and political consciousness."

\section{Conclusion}

Teaching reform of ideological and political education in Sichuan Agricultural University shows that we must grasp the principle of "three do's and three don'ts." in consolidating the key points of "education and self-education classroom system". To grasp the progress and depth of the implementation of the theme of education and teaching, to reflect the rigor and scientific nature of theoretical study instead of discussing for discussion. To make good use of the local students' interest, the relevant teaching and learning resources of school, the hot resources of current politics, professional resources and human resources to serve the educational theme and to increase their attractiveness and realize the organic interaction both inside and outside the subject. To combine passionate teaching and rational analysis, do not repeat what the book says or speak carelessly. Display the learning charm of Marxist theory through the interaction between teachers and students in a limited time and space, so that students truly understand, believe and use Marxism from the bottom of heart, laying the cornerstone of Marxism belief in the education and self-education system. The realization of teaching effect relies on effective teaching methods. Former Soviet educator Бабанский believes that "one of the most important and most difficult problems in the optimization of teaching methods is the rational selection of teaching methods and their attainment of a combination, that is to obtain the best teaching effect within a limited time frame". Sichuan Agricultural University optimizes the combination of heuristic, inquiry, discussion and participatory teaching in constructing the "education and self-education classroom system" of college students. Through motivating the students' curiosity and interest points, a good environment with independent thinking, free exploration and innovation [1] is created for the students and won recognition. Teaching reform experiment itself also shows that education of ideology and politics is "a dynamic process that operates regularly and in a certain way"[8]. Make the best use of circumstances and teach students in accordance with their aptitudes are the unremitting pursuit of experimental teaching. 


\section{References}

[1] National Leading Group for Reform in Medium and Long-term Education Reform and Development. Outline of National Medium-and Long-Term Program for Education Reform and Development (2010-2020).

[2] American, Carl R. Rogers. Freedom to Learn [M]. New Jersey: Prentice Hall Publishing Company, 1994: 185-187.

[3] Shen Zhuanghai. Effectiveness of Ideological and Political Education [M]. Wuhan: Wuhan University Press, 2001: 79.

[4] Confucian Analects - Government Exercises. Compiled by Confucius' disciples and their followers.

[5] American, Anthony Orum. Introduction to Political Sociology [M]. Dong Yunhu, Li Yunlong translation, Hangzhou: Zhejiang People's Publishing House, 1989: 365.

[6] Wang Xuejian. Frontier Research of Modern Ideological and Political Education [M]. Beijing: People's Publishing House, 2008: 97.

[7] American, Saundra Hybels. Communicating Effectively [M]. Li Yakun translation, Beijing: Huaxia Publishing House, 2001: 119.

[8] Qiu Weiguang et al.: Principles of Ideological and Political Education [M]. Beijing: Higher Education Press, 1999: 206. 